\title{
Effects of sulphapyridine on sperm transport through the rat epididymis and contractility of the epididymal duct
}

\author{
G. Chaturapanich, K. Sujarit and C. Pholpramool* \\ Department of Physiology, Faculty of Science, Mahidol University, Rama VI Road, Bangkok 10400, Thailand
}

\begin{abstract}
This study was undertaken to investigate the effects of sulphapyridine on the transport of spermatozoa through different regions of the epididymis and on the contractility of the epididymal duct in the rat. Sperm transport was investigated by labelling testicular spermatozoa with $\left[{ }^{3} \mathrm{H}\right]$ thymidine and measuring intraluminal pressures of the epididymis by micropuncture, using a servo-nulling pressure transducer system. In control rats, the transit times of epididymal spermatozoa from the initial segment to the caput, from the caput to the proximal cauda, and from the proximal cauda to the distal cauda were 2, 6 and 3 days, respectively, giving a total transit time of 11 days. The total transit time was shortened to 8 days after treatment with sulphapyridine at a dosage of $450 \mathrm{mg} \mathrm{kg}^{-1}$ for 38-52 days. The rate of sperm transport was most affected in the caput epididymidis. Measurements of intraluminal pressures showed that sulphapyridine had no effect on spontaneous contractions in any regions of the epididymis. However, the frequency of contraction of the corpus and cauda epididymides in response to administration of $10 \mu \mathrm{g}$ noradrenaline $\mathrm{kg}^{-1}$ in the sulphapyridine-treated rats was significantly higher $(P<0.05)$ than it was in the controls. Methacholine, at a dose of 20 $\mu \mathrm{g} \mathrm{kg}^{-1}$, produced a smaller increase in basal pressure in the caput epididymidis of sulphapyridine-treated rats $(P<0.05)$ compared with controls. The results led to the conclusion that sulphapyridine increases the rate of sperm transport from the caput through the cauda epididymidis, in part, by changes in the responsiveness of the epididymis to the autonomic nervous system.
\end{abstract}

\section{Introduction}

Sulphapyridine is a metabolic product of sulphasalazine, which has been used for treatment of ulcerative colitis. Male patients who received sulphasalazine treatment became infertile but recovered after drug withdrawal (Peppercorn and Goldman, 1972; Levi et al., 1979). The sulphapyridine moiety is the active component in suppression of fertility in men (O'Morain et al., 1982a,b) and rats (O'Morain et al., 1982b; Pholpramool and Srikhao, 1985). In rats, sulphapyridine did not affect testicular mass, concentrations of gonadotrophin and testosterone in blood, or spermatogenesis (Pholpramool and Srikhao, 1983, 1985; O'Morain et al., 1984; Pholpramool et al., 1989). In addition, Wong et al. (1987) showed that sulphapyridine, the most effective antifertility sulfonamide, could pass into the epididymal fluid. It is likely that the site of action of sulphapyridine is post-testicular, possibly at the epididymis, although the mechanism of action is still unknown.

Spermatozoa require an optimal transit time through the epididymis to attain the ability to be motile and to fertilize ova. The transit time through the epididymis, which is species dependent, is approximately 8-15 days (Orgebin-

*Correspondence

Revised manuscript received 25 May 1999.
Crist, 1965; Bedford, 1975; Robb et al., 1978). Transport of spermatozoa through the epididymis is mainly the result of spontaneous contractions of the smooth muscle surrounding the epididymal duct, and can be modified by hormones (Hib and Ponzio, 1977; Din-Udom et al., 1985) and by cholinergic and adrenergic drugs (Hib, 1976; Laitinen and Talo, 1981; Pholpramool and Triphrom, 1984). The passage of labelled spermatozoa through the epididymis is enhanced by castration (Dyson and Orgebin-Crist, 1973; Sujarit and Pholpramool, 1985). This effect may be due to the increase in amplitude and frequency of epididymal contractions (DinUdom et al., 1985). It has been reported that an acceleration of sperm transport by the transplantation of a Silastic implant containing methoxamine, an $\alpha$-adrenergic agonist, near the epididymis produced rapid infertility in male rats (Ratnasooriya et al., 1980). However, tamsulosin which is an $\alpha$-adrenergic antagonist, has been demonstrated to induce antifertility (Ratnasooriya and Wadsworth, 1994). Another antagonist, bunazosin, was found to increase sperm concentration and intraluminal fluid movement in the cauda epididymidis while decreasing the epididymal intraluminal pressure in rats (Yamamoto et al., 1995). These reports led to the proposal that an abnormal transit time of spermatozoa in the epididymis is associated with male infertility.

In the present study, the effects of sulphapyridine on (1) sperm transport through the epididymis, by labelling Downloaded from Bioscientifica.com at 04/26/2023 11:26:17AM 
intratesticular spermatozoa with $\left[{ }^{3} \mathrm{H}\right]$ thymidine; and (2) the spontaneous contractions of rat epididymis in vivo, as well as the responsiveness of the epididymis to adrenergic and cholinergic agonists, were investigated.

\section{Materials and Methods}

\section{Animals}

Sexually mature male (320-400 g) and female (200-250 g) Wistar rats were obtained from the National Animal Center, Mahidol University. Males were kept separately in stainlesssteel hanging cages at ambient temperature and under a $12 \mathrm{~h}$ light:12 h dark lighting regimen with free access to food and water.

\section{Chemicals}

All chemicals used for measurement of sperm transit time were reagent grade and were obtained from Sigma (St Louis, $\mathrm{MO}$ ) except for $\left[{ }^{3} \mathrm{H}\right]$ thymidine (Amersham International plc, Amersham). Methacholine chloride (acetyl- $\beta$-methylcholine chloride) and (-)noradrenaline bitartrate were also purchased from Sigma.

\section{Experiment 1: measurement of sperm transit time}

Fertility testing. The fertility of the male rats was assessed by natural mating using the method of Pholpramool et al. (1991). Each male rat was kept with two virgin female rats for 1 week. Successful mating was verified by the presence of spermatozoa in the vaginal smears taken every morning. After 1 week of cohabitation, both females were removed from the male, kept separately for 8-10 days, and then killed by an overdose of diethyl ether (Sigma) for confirmation of pregnancy. The number of fetuses and corpora lutea were determined by use of a dissecting microscope.

The fertility of the male rats was expressed as the percentage fertility, calculated from the ratio of the number of fetuses to the number of corpora lutea times one hundred. When both female rats were impregnated by the same male, the average value was used. Only male rats that had a high fertility rate $(>80 \%$ ) were used in the experiment.

Labelling of spermatozoa. The testicular spermatozoa were labelled using $\left[{ }^{3} \mathrm{H}\right]$ thymidine as described by Sujarit and Pholpramool (1985). Briefly, each rat was injected with a single dose of $15 \mu \mathrm{Ci}\left[{ }^{3} \mathrm{H}\right]$ thymidine ([methyl- ${ }^{3} \mathrm{H}$ ] thymidine, sp. act. $25 \mathrm{Ci} \mathrm{mmol}^{-1}$; Amersham International plc), dissolved in $0.2 \mathrm{ml}$ normal saline into both testes under light ether anaesthesia.

Sulphapyridine treatment. After receiving an intratesticular injection of $\left[{ }^{3} \mathrm{H}\right]$ thymidine, male rats were fed every day via gastric intubation with sulphapyridine suspended in corn oil at a dose of $450 \mathrm{mg} \mathrm{kg}^{-1}$, which was the dose that caused maximal suppression of fertility in rats (Pholpramool et al.,
1991). The rats were assigned randomly to six groups of 6-8 animals, weighing about $320 \mathrm{~g}$ at the start of the treatment. They were then returned to their cages and kept for 38-52 days. On days $38,40,44,46,49$ and 52, rats were killed by an overdose of sodium pentobarbitone (Sanofi Sante Animale SA, Paris). Each series of experiments also contained groups of 8-12 control male rats which were fed corn oil only. All rats were weighed before each feeding.

Recovery of spermatozoa. Labelled spermatozoa in the male reproductive tract, the epididymis (the initial segment, the caput, the corpus, and the proximal and distal cauda), and the vas deferens were collected according to the method of Sujarit and Pholpramool (1985). The total radioactivity in each area was measured by a liquid scintillation method. The results were then expressed as a percentage of the total radioactivity (d.p.m.) in the whole epididymis per $10^{6}$ spermatozoa (Sujarit and Pholpramool, 1985).

The estimated transit time of the epididymal spermatozoa was calculated by the method of Sujarit and Pholpramool (1985), that is, calculated from the time difference between peaks of radioactivity in two adjacent regions of the epididymis.

\section{Experiment 2: micropuncture and measurements of intraluminal pressures}

The testis and the epididymis were prepared for micropuncture and intraluminal pressure measurement according to Pholpramool and Triphrom (1984). The bath temperature was set at $34^{\circ} \mathrm{C}$. The sites of pressure measurements in the epididymis were the proximal-caput (site 2), the mid-corpus (site 4) and the proximal-cauda (site 6), according to Hinton et al. (1979). The parameters measured in this study were basal pressure, amplitude and frequency of contraction.

Experiment 2.1: effect of sulphapyridine on spontaneous contraction. A group of 32 rats was divided randomly into two groups. The first group of rats was fed with sulphapyridine dissolved in corn oil at a dose of $450 \mathrm{mg} \mathrm{kg}^{-1}$ body weight for 5 weeks. This treatment caused a reduction in fertility to $25.9 \%$ of control (Pholpramool et al., 1991). The second group of rats received only corn oil for 5 weeks and served as controls. At the end of treatment, the animals were prepared for micropuncture and measurements of intraluminal pressure of the epididymis as described above.

Experiment 2.2: effect of adrenergic agonist (noradrenaline). This part of the study was carried out in 16 corn oil treated and 16 sulphapyridine-treated rats. After a steady intraluminal pressure recording was established for at least 5 min, noradrenaline $\left(10 \mu \mathrm{g} \mathrm{kg}^{-1}\right)$ was administered through a jugular vein catheter and intraluminal pressure was measured until the effect of noradrenaline subsided. This programme was repeated using 20 and $40 \mu \mathrm{g} \mathrm{kg}^{-1}$ doses to obtain a dose-response curve. The measurements were repeated in two areas in each animal. The sequence of micropuncture in each animal was random. 
Experiment 2.3: effect of a cholinergic agonist (methacholine). This part of the study was carried out in eight control and eight sulphapyridine-treated rats. The experimental procedure was similar to that described in Expt 2.2. A dose of $20 \mu \mathrm{g}$ methacholine $\mathrm{kg}^{-1}$ was given in this experiment to test the effect of this cholinergic agonist.

All drugs were prepared freshly in normal saline at $\mathrm{pH} 7.4$ and were given in a volume of $0.1 \mathrm{ml}$. Injection of saline alone had no effect on the intraluminal pressure recordings.

\section{Statistical analyses}

All results are presented as mean \pm SEM. Differences between control and treatment groups were determined using an unpaired Student's $t$ test. A $P$ value of $<0.05$ was considered to indicate a significant difference.

\section{Results}

\section{Effect of sulphapyridine on transport of spermatozoa in different regions of the epididymis}

Sulphapyridine enhanced the transport of labelled spermatozoa from the caput to the cauda epididymidis of the rats. By 38 days after intratesticular injection of $\left[{ }^{3} \mathrm{H}\right]$ thymidine, the peak amount of labelled spermatozoa that appeared in the initial segment in the sulphapyridinetreated rats was not different from that of the corn oil-treated rats (Fig. 1a). However, in general, from day 40 to day 49 , the transport of spermatozoa from the caput to the vas deferens in the sulphapyridine-treated rats was faster than it was in the control rats (Fig. 1b-f). The mass of labelled spermatozoa in the corn oil-treated rats had reached the proximal and the distal cauda epididymides by days 46 and 49 , respectively (Fig. 1d,e) while, by day 49 , most of the labelled spermatozoa in the sulphapyridine-treated rats had already moved into the vas deferens. By day 52, most of the labelled spermatozoa in both groups were found in the distal cauda epididymidis and the vas deferens. In the control group, the transit times of the epididymal spermatozoa from the initial segment to the caput, from the caput to the proximal cauda, and from the proximal cauda to the distal cauda were 2, 6 and 3 days, respectively. Thus, the total transit time from the initial segment to the distal cauda epididymidis was approximately 11 days. However, in the sulphapyridine-treated rats, the times required for sperm transport through the caput, the corpus and the cauda epididymides (the transit time of the epididymal spermatozoa from the initial segment to the caput, from the caput to the proximal cauda, and from the proximal cauda to the distal cauda) were, 2,4 and 2 days, respectively, giving a total transit time of approximately 8 days.

\section{Effects of sulphapyridine on spontaneous contractions}

In the control rats, the basal pressures and the amplitude of contractions in the caput and the corpus epidiymides were
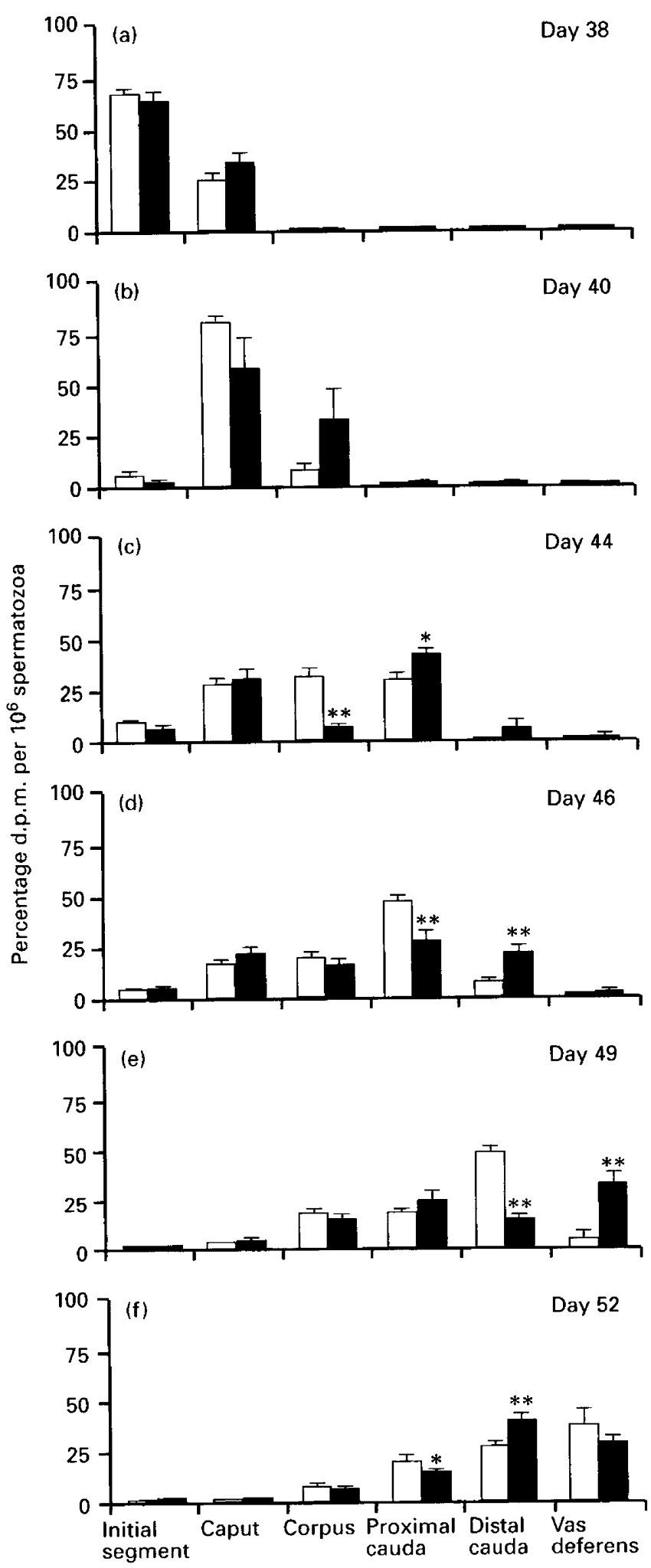

Fig. 1. Percentage distribution of labelled spermatozoa in different regions of the epididymis: the initial segment; the caput, the corpus, the proximal and distal cauda epididymides; and the vas deferens of rats after feeding with corn oil ( $\square$ ) or $450 \mathrm{mg}$ sulphapyridine $\mathrm{kg}^{-1}$ (ם) for 38-52 days. Values are mean \pm SEM from $6-12$ rats. Asterisks indicate significant differences $\left({ }^{*} P<0.05 ;{ }^{* * P}<0.01\right.$ ). 
not different, but these pressures were significantly lower $(P<0.01)$ than they were in the cauda epididymidis. Similarly, there were no differences in the frequency of contractions of the caput and the corpus epididymides. However, the rhythmic activities in these two regions were significantly higher $(P<0.01)$ than they were in the cauda epididymidis.

Sulphapyridine had no effect on the basal pressure or on the amplitude and frequency of contraction in any region of the rat epididymis when compared with controls (Fig. 2a,b).

\section{Effects of sulphapyridine on the responsiveness of epididymis to noradrenaline and methacholine}

Dose-response curves of the epididymal contractions after administration of noradrenaline in the corn oil and sulphapyridine-treated rats are shown (Fig. 3). Sulphapyridine had no effect on the contractility of the caput epididymidis in response to various doses of noradrenaline when compared with controls. However, sulphapyridine caused significant increases in the frequency of contractions of the corpus and cauda epididymides in response to low doses of noradrenaline, while noradrenaline-induced increases in basal pressures and the amplitude of contractions were not affected by the antifertility drug. When the responsiveness of the caput and cauda epididymides to methacholine was investigated, the contractility of these segments was not altered by sulphapyridine, except for the increase in basal pressure of the caput epididymidis, which was smaller in the sulphapyridine-treated rats (Table 1).

\section{Discussion}

Although Wong et al. (1987) and Pholpramool et al. (1989) suggested that the site of action of sulphapyridine is likely to be the epididymis, very little is known of the mode of action of sulphapyridine in causing reversible suppression of fertility in males. The present study elucidated the effect of sulphapyridine on sperm transport through the rat epididymis by labelling intratesticular spermatozoa with $\left[{ }^{3} \mathrm{H}\right]$ thymidine. It was found that sulphapyridine did not


Fig. 2. Intraluminal pressures and frequency of contractions in different regions of the epididymis in control ( $\square$ ) and sulphapyridine-treated ( $\boldsymbol{\square}$ ) rats. (a) Basal pressure (bottom bar) and amplitude of contraction (top bar); (b) frequency of contraction. Values are mean + SEM from $8-15$ rats.

change the transit time of spermatozoa in the initial segment. However, the results demonstrated that the rate of sperm transport from the caput to the distal cauda epididymidis in the sulphapyridine-treated rats was about 3 days faster than that found in the controls. The effect was greater in the transport from the caput to the proximal cauda epididymidis. Maturation of spermatozoa takes place during their transit from the caput to the cauda epididymidis in several species, including rats (Bedford, 1975).

The enhancement of sperm transport in the cryptic epididymis of rabbits is associated with a reduction in sperm

Table 1. Effect of methacholine $\left(20 \mu \mathrm{kg}^{-1}\right.$, i.v.) on the intraluminal pressure and contractility of the epididymis in control and sulphapyridine-treated rats

\begin{tabular}{|c|c|c|c|c|c|c|}
\hline \multirow[b]{3}{*}{ Epididymal segment } & \multirow{2}{*}{\multicolumn{2}{|c|}{ Basal pressure $\left(\mathrm{cm} \mathrm{H}_{2} \mathrm{O}\right)$}} & \multicolumn{4}{|c|}{ Contraction } \\
\hline & & & \multicolumn{2}{|c|}{ Amplitude $\left(\mathrm{cm} \mathrm{H}_{2} \mathrm{O}\right)$} & \multicolumn{2}{|c|}{ Frequency (contractions $\mathrm{min}^{-1}$ ) } \\
\hline & Control & Sulphapyridine & Control & Sulphapyridine & Control & Sulphapyridine \\
\hline \multicolumn{7}{|l|}{ Mid-caput } \\
\hline Before drug & $5.0 \pm 0.5(5)$ & $4.2 \pm 0.6(4)$ & $3.1 \pm 0.2(5)$ & $3.1 \pm 0.3(4)$ & $6.9 \pm 0.7(5)$ & $7.3 \pm 0.7(4)$ \\
\hline $\begin{array}{l}\text { After drug } \\
\text { Mid-cauda }\end{array}$ & $8.3 \pm 0.9(4)$ & $6.0 \pm 0.3^{*}(4)$ & $3.1 \pm 0.5(4)$ & $2.6 \pm 0.3(4)$ & $11.0 \pm 1.3(4)$ & $10.3 \pm 1.1(4)$ \\
\hline Before drug & $6.8 \pm 0.9(5)$ & $6.3 \pm 1.2(5)$ & $10.0 \pm 1.1(5)$ & $12.3 \pm 1.2(5)$ & $2.4 \pm 0.6(5)$ & $2.7 \pm 0.7(5)$ \\
\hline After drug & $11.8 \pm 3.4(5)$ & $8.0 \pm 1.7(5)$ & $12.4 \pm 1.3(5)$ & $13.5 \pm 1.1(5)$ & $5.6 \pm 1.9(5)$ & $5.0 \pm 1.5(5)$ \\
\hline
\end{tabular}

Values are mean \pm SEM from number of rats in the parentheses.

* Significantly different $(P<0.05)$ from corresponding control value. 

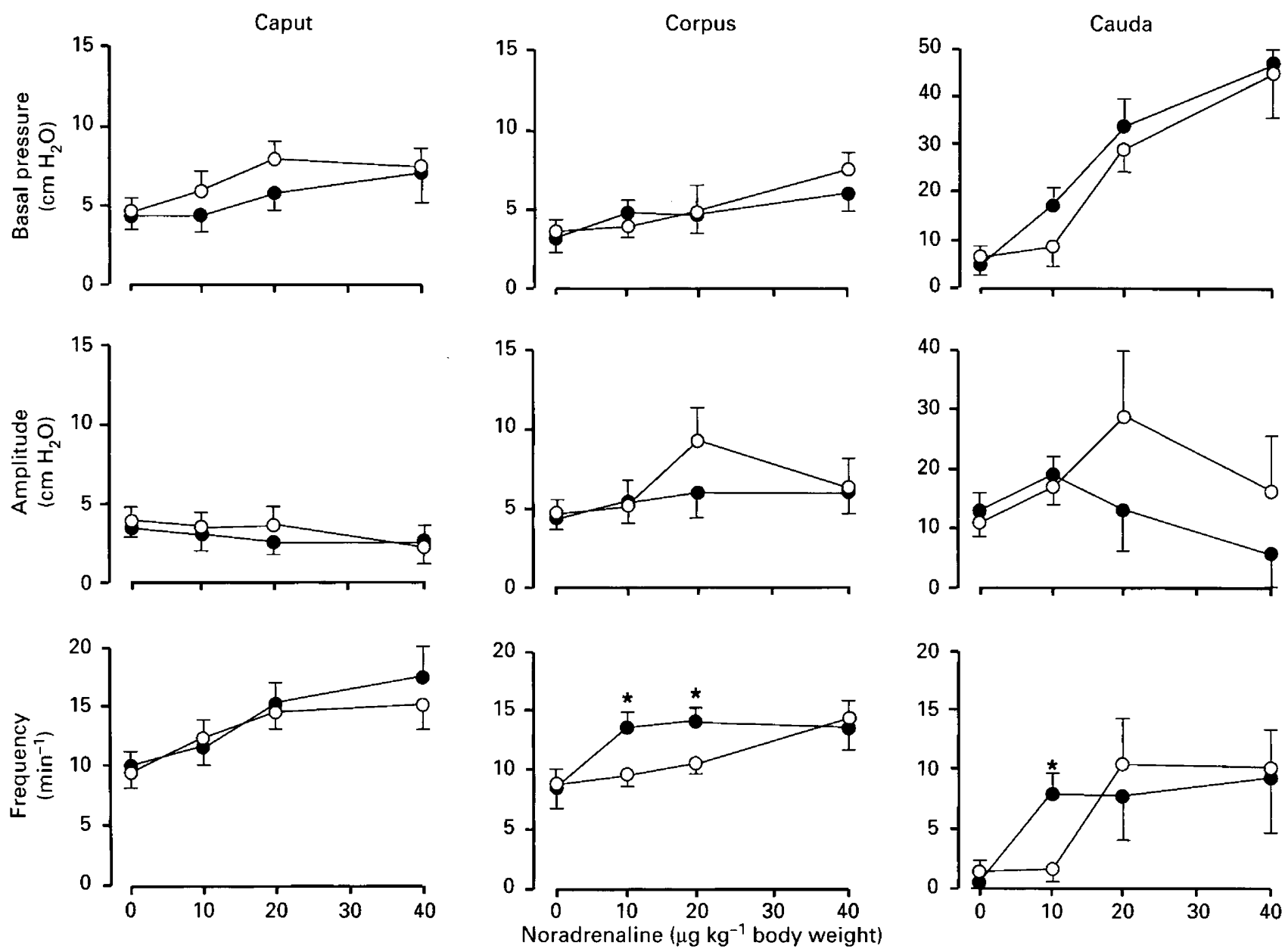

Fig. 3. Dose-response curves of noradrenaline-induced contractions (basal pressure, amplitude and frequency of contraction) of the caput, corpus and cauda epididymides in the control $(O)$ and sulphapyridine-treated $(O)$ rats. Values are mean \pm SEM from $4-14$ rats. Asterisks indicate significant differences $(P<0.05)$.

motility and fertility rate (Bedford, 1978). Ratnasooriya $e t$ al. (1980) reported that local application of a sympathomimetic drug, methoxamine, to the epididymis caused a marked reduction in the fertility of the male rats. This effect was explained in terms of an increase in the rate of sperm transit through the epididymis by a methoxamine-induced enhancement of the rhythmic contraction of the tubule. Therefore, the results of the present study indicate that sulphapyridine suppresses male fertility, probably by increasing the rate of sperm transport through the epididymis.

Maturation of spermatozoa takes place in the proximal and middle regions of the epididymis in most species. This process probably involves interactions between spermatozoa and epididymal secretion leading to changes in sperm surface proteins, in addition to interactions between spermatozoa and the apical membrane of the epididymal epithelium (Cooper, 1998). Therefore, it is possible that incomplete interactions and, hence, sperm maturation occur if the rate of sperm transport through the epididymis is accelerated (that is, if transit time is decreased).

The mechanism by which sulphapyridine decreases sperm transit time is unclear. However, there are at least three possibilities by which sperm transport through the epididymis may be enhanced.

First, fluid flow from the testis may be increased. However, there is no evidence to indicate a stimulatory effect of sulphapyridine on fluid secretion by the seminiferous tubules. Neither has the influence of this drug on fluid reabsorption by the ductuli efferentes been reported. Although the rate of sperm production could affect sperm transit, daily sperm production is not altered by sulphapyridine treatment (Pholpramool et al., 1989). The present study also showed that sulphapyridine had no effect on sperm transit through the initial segment and the proximal caput (Fig. 1).

Second, there may be an increase in contractility of smooth muscle surrounding the duct. Transportation of spermatozoa through the epididymis was faster after androgen deprivation, and sperm transport was restored to normal when testosterone was administered to castrated rats (Pholpramool et al., 1982; Sujarit and Pholpramool, 1985). This effect was probably the result of an increase in contractility of the epididymis, since Din-Udom et al. (1985) reported that the rat epididymis contracted more frequently and more forcefully after castration. However, the Downloaded from Bioscientifica.com at 04/26/2023 11:26:17AM 
enhancement of sperm transport through the epididymis of rats receiving sulphapyridine in the present study was probably not due to changes in the spontaneous contractions since the basal pressure, amplitude of contraction, total pressure and frequency of contraction at any region of the epididymis were not affected by sulphapyridine treatment. These results are in agreement with the finding that the concentration of testosterone in the blood was not changed after an antifertility dose of sulphapyridine (Pholpramool et al., 1989). However, there were changes in the responsiveness of the epididymis to noradrenaline. Hence, the corpus and cauda epididymides contracted more frequently in sulphapyridine-treated rats than in controls when $10 \mu \mathrm{g}$ noradrenaline $\mathrm{kg}^{-1}$ was administered. These segments of the epididymis are innervated by adrenergic terminals (El-Badawi and Schenk, 1967). The increase in the responsiveness of the corpus and cauda epididymides to adrenergic activities after sulphapyridine treatment may account for the decreased transit time of labelled spermatozoa in these regions. The mechanism by which sulphapyridine caused changes in the responsiveness to noradrenaline in the present study is not clear. There has been no report on the effect of sulphapyridine or other sulpha drugs on autonomic control in other systems. However, the results of the present study indicate that sulphapyridine probably had no effect on the control of blood pressure, since systemic arterial pressures in the control and sulphapyridine-treated rats were not different before or after administration of noradrenaline (data not shown).

Third, spermatozoa may move faster through the epididymis if the resistance to flow is reduced. This reduction in resistance may be accomplished by an increase in luminal diameter of the epididymal duct or a decrease in fluid viscosity. Luminal diameter in the caput, corpus and cauda epididymides did not change after administration of $500 \mathrm{mg}$ sulphapyridine $\mathrm{kg}^{-1}$ per day for 5 weeks (Srikhao, 1987). However, administration of $450 \mathrm{mg}$ sulphapyridine $\mathrm{kg}^{-1}$ per day for 5 weeks caused a substantial decrease in sperm concentration in the caput and cauda fluid removed by micropuncture technique (Bunnag et al., 1992). Although the effect of sulphapyridine on the transport activities of the epididymal epithelium has not been elucidated, it is possible that increased luminal fluid caused by an inhibition of fluid absorption or enhancement of fluid secretion reduces the spermatocrit, decreasing luminal viscosity and leading to an enhancement of epididymal sperm transport.

In conclusion, the present study investigated the effects of sulphapyridine on the transport of spermatozoa through the rat epididymis and on the contractility of the epididymal duct. Sulphapyridine increased the rate of sperm transport from the caput to the distal cauda epididymis by approximately 3 days. The decrease in transit time may be associated, in part, with changes in the responsiveness of the epididymis to adrenergic nerve activities and a reduction in spermatocrit.

This work was supported, in part, by research grants from the Thai National Research Council of Thailand and USAID (US-Israel CDR Programme). The authors gratefully acknowledge L.M. Lewin and K. K. Shida Pang for giving useful comments on the manuscript. They also thank R. Chaiyot and S. Chantchaemsai for their expert technical assistance and C. Sapeeya for typing the manuscript.

\section{References}

Bedford JM (1975) Maturation, transport, and fate of spermatozoa in the epididymis. In Handbook of Physiology, Section 7, Vol. 5 Male Reproductive System pp 303-317 Eds DW Hamilton and RO Greep. American Physiological Society, Washington DC

Bedford JM (1978) Influence of abdominal temperature on epididymal function in the rat and rabbit American Journal of Anatomy 152 509-522

Bunnag D, Chaturapanich G, Lewin LM and Pholpramool C (1992) Alterations of epididymal sperm surface proteins by some antifertility agents in the rat Thai Journal of Physiological Sciences 5 27-39

Cooper TG (1998) Interactions between epididymal secretion and spermatozoa Journal of Reproduction and Fertility Supplement 53 119-136

Din-Udom A, Sujarit S and Pholpramool C (1985) Short-term effect of androgen deprivation on intraluminal pressure and contractility of the rat epididymis Journal of Reproduction and Fertility 73 405-410

Dyson ALMB and Orgebin-Crist MC (1973) Effect of hypophysectomy, castration and androgen replacement upon the fertilizing ability of rat epididymal spermatozoa Endocrinology 93 391-402

El-Badawi A and Schenk EA (1967) The distribution of cholinergic and adrenergic nerves in the mammalian epididymis American Journal of Anatomy 121 1-14

Hib J (1976) Effects of autonomic drugs on epididymal contractions Fertility and Sterility $27951-956$

Hib J and Ponzio RO (1977) Effect of efferent duct ligation, gonadectomy and testosterone replacement on epididymal contractility in the rat Journal of Reproduction and Fertility 50327-329

Hinton BT, Dott HM and Setchell BP (1979) Measurement of the motility of rat spermatozoa collected by micropuncture from the testis and from different regions along the epididymis Journal of Reproduction and Fertility $\mathbf{5 5}$ $167-172$

Laitinen L and Talo A (1981) Effects of adrenergic and cholinergic drugs on electrical and mechanical activities of the rat cauda epididymidis in vitro. Journal of Reproduction and Fertility 63 205-209

Levi AJ, Fischer AM, Hughes L and Hendry WF (1979) Male infertility due to sulphasalazine Lancet 2 276-278

O'Morain C, Smethurst P, Hudson E and Levi AJ (1982a) Further studies on sulphasalazine induced male infertility Gastroenterology $821140 \mathrm{~A}$

O'Morain C, Smethurst P and Levi AJ (1982b) Sulfasalazine induced reversible male infertility in man and rat Gut 23 A892

O'Morain C, Smethurst P and Dore CI (1984) Reversible male infertility due to sulphasalazine. Studies in man and rats Gut 25 1078-1084

Orgebin-Crist MC (1965) Passage of spermatozoa labelled with thymidine ${ }^{3} \mathbf{H}$ through the ductus epididymidis of the rabbit Journal of Reproduction and Fertility 10241-251

Peppercorn MA and Goldman P (1972) The role of intestinal bacteria in the metabolism of salicylazosulfapyridine fournal of Pharmacology and Experimental Therapeutics 181 555-561

Pholpramool C and Srikhao A (1983) Antifertility effect of sulfasalazine in the male rat Contraception 28 273-279

Pholpramool C and Srikhao A (1985) Suppression of fertility by sulfasalazine and its metabolites in male rats Journal of Andrology Supplement 650

Pholpramool C and Triphrom N (1984) Effects of cholinergic and adrenergic drugs on intraluminal pressures and contractility of the rat testis and epididymis in vivo. Journal of Reproduction and Fertility 71 181-188

Pholpramool C, White RW and Setchell BP (1982) Influence of androgens on inositol secretion and sperm transport in the epididymis of rats Journal of Reproduction and Fertitity $66547-553$

Pholpramool C, Verawatnapakul V, Srikhao A, Ruchirawat S and Lewin LM (1989) Lack of effects of some antifertility sulfonamides on testicular functions in the male rat Proceedings of the 4th International Congress of Andrology Florence, pp 27-31

Pholpramool C, Ruchirawat S, Verawatnapakul V, Paovalo C and Lewin LM (1991) Structural requirements of some sulfonamides that possess an antifertility activity in male rats Journal of Reproduction and Fertility $92169-178$

Ratanasooriya WD and Wadsworth RM (1994) Tamsulosin, a selective $\alpha 1$ adrenoceptor antagonist, inhibits fertility of male rats Andrology 26 107-110 Downloaded from Bioscientifica.com at $04 / 26 / 2023$ 11:26:17AM 
Ratnasooriya WD, Gilmore DP and Wadsworth RM (1980) Effect of local application of sympathomimetic drugs to the epididymis on fertility in rats Journal of Reproduction and Fertility 58 19-25

Robb GW, Amann RP and Killian GJ (1978) Daily sperm production and epididymal sperm reserves of pubertal and adult rats Journal of Reproduction and Fertility 54 103-107

Srikhao A (1987) Antifertility Effects of Sulfasalazine and its Toxicity in Male Rats PhD Thesis, Mahidol University

Sujarit S and Pholpramool C (1985) Enhancement of sperm transport through the rat epididymis after castration Journal of Reproduction and Fertility $\mathbf{7 4}$ 497-502

Wong PYD, Lau SKD and Fu WO (1987) Antifertility effects of some sulphonamides and related compounds and their accumulation in the epididymides of male rats Journal of Reproduction and Fertility 81 259-267

Yamamoto M, Hibi $\mathbf{H}$ and Miyake $\mathbf{K}$ (1995) Effects of alpha blocker on daily testicular sperm production and sperm concentration, motility, intraluminal pressure and fluid movement in the rat epididymis Tohoku Journal of Experimental Medicine 177 25-37 